The Meter of Tohono O'odham Songs

Author(s): Colleen M. Fitzgerald

Source: International Journal of American Linguistics, Vol. 64, No. 1 (Jan., 1998), pp. 1-36

Published by: The University of Chicago Press

Stable URL: http://www.jstor.org/stable/1265644

Accessed: 11-08-2014 20:10 UTC

Your use of the JSTOR archive indicates your acceptance of the Terms \& Conditions of Use, available at http://www.jstor.org/page/info/about/policies/terms.jsp

JSTOR is a not-for-profit service that helps scholars, researchers, and students discover, use, and build upon a wide range of content in a trusted digital archive. We use information technology and tools to increase productivity and facilitate new forms of scholarship. For more information about JSTOR, please contact support@jstor.org. 


\title{
THE METER OF TOHONO O'ODHAM SONGS ${ }^{1}$
}

\author{
Colleen M. Fitzgerald
}

San José State University

1. Introduction. The evaluation of poetry and songs has been essential to the progress of generative metrical theory. ${ }^{2}$ The bulk of work done in generative metrics focuses on English poetry (although Kiparsky 1968, Maling 1973, and Prince 1989 are some notable exceptions). Limitations of such a focus become evident when metricists make typological claims, as in Hayes (1989). Research on the meter of other languages is thus critical for a valid typology of meter and metrical rules. With such a goal in mind, I examine the meter of Tohono O'odham songs. Tohono O'odham (henceforth TO; formerly Papago) is a Native American language of the Uto-Aztecan family spoken in southern Arizona. We find that the abstract metrical pattern of these songs provides a valuable test for theories of meter, such as those advanced in Hayes (1989). The songs comprise part of an oral tradition and represent an instance of meter which is Native American rather than Indo-European. These two characteristics unite to produce a metrical system which differs from that of English poetry.

Here I give both a description and an analysis of the meter of previously unanalyzed Tohono O'odham traditional songs. The crucial problem is characterizing the line. Song lines are flexible in the number of syllables and stresses that they allow, but are not completely unconstrained. The positioning of stressed material is strictly regulated, as stresses are prohibited from

\footnotetext{
${ }^{1}$ Many people have given helpful comments along the way, including the participants of the 1993 Western Conference on Linguistics, Seattle, Washington. The following have responded to written versions of this paper: Mike Hammond, Jane Hill, Ofelia Zepeda, Ken Hale, Gilbert Youmans, Donald Bahr, David Rood, Andrea Heiberg, Leanne Hinton, Terry Langendoen, Peg Lewis, Diane Ohala, Pat Pérez, and an anonymous reviewer for this Journal. I owe a very special thanks to Mike Hammond for extensive input on multiple drafts and to Ofelia Zepeda for important help in translating the song material. Any errors are my own. For surface forms, I use the official orthography of the Tohono O'odham nation, which was developed by Albert Alvarez and Ken Hale. This orthography approximates a phonemic transcription. I modify the orthography slightly and mark primary stress, which is not represented in the official orthography.

${ }^{2}$ The term "metrical" is used in two ways: (1) "A theory of phonology in which phonological strings are represented in a hierarchical manner, using such notions as segment, syllable, foot and word (cf. also prosodic phonology). Originally introduced as a hierarchical theory of stress, the approach now covers the whole domain of syllable structure and phonological boundaries" (Crystal 1991:218). (2) The (linguistic) study of versification, as in poetry and songs. I use the second sense of this term, except when referring to the metrical grid of Hayes $(1983 ; 1989)$.
} 
appearing adjacent to another stress, or in the second and final metrical positions of a line. I argue for binary trochaic feet, built at left edges and wherever stressed syllables occur; stresses are further prohibited from appearing in weak position. The analysis has four results: (1) lines are flexible in some traditions; (2) binary feet, with constituency, are necessary; (3) poetic meter is shown to invoke morphology to satisfy constraints on the meter; and (4) metrical rules for left edges may be strict, contra Hayes (1989).

This study also has relevance beyond meter, specifically for phonological theory and the study of Native American literature. Recent work in phonology has focused on the nature of constraints, particularly work in Optimality Theory (McCarthy and Prince 1993 and Prince and Smolensky 1993). Optimality Theory argues that constraints may be violable or undominated (and inviolable); here I show evidence from meter for two inviolable constraints which govern the meter (the Edge Constraint and the Binary Foot Constraint). To prevent violations, the morphology is systematically manipulated. The TO meter provides one example of how a constraint governed system in meter operates (see Hayes 1993 for specific discussion of relevant issues for meter and optimization).

This study is also germane to work on Native American literature, as it shows that oral literature, here the songs, may have a system of meter comparable to those found in written literature, such as the poetry of William Shakespeare. Hinton $(1984 ; 1990)$ looks at the meter of Havasupai songs from a linguistic perspective. This paper takes a similar approach. This type of work furthers recognition of Native American songs, narratives, and speeches as a valid and important body of literature.

This paper is structured as follows. The first section gives the necessary background on the theory of meter. This is followed by background on reduplication and stress in Tohono O'odham and a description of the songs. The second section presents the analysis of the song meter discussed above. In the third section, I discuss implications of this analysis for the theory of meter proposed in Hayes (1989). Specifically, I examine his typological claims for metrical rules and show that the typology must be expanded to account for the strict left-edge meter presented here. Finally, I conclude the paper with a discussion of the importance of the study for metrical theory.

2. Background. This section provides the theoretical and descriptive underpinnings necessary for an analysis of the TO song meter. Section $\mathbf{2 . 1}$ briefly gives background on meter and generative metrics. This is followed (2.2) with a discussion of the necessary descriptive facts, both of TO phonology and the songs, which are especially important to determine how to 
characterize this meter and, just as important, to determine how this meter cannot be characterized. Section 2.3 looks at the relevant facts of TO phonology, while $\mathbf{2 . 4}$ provides background on the song format and the songs themselves.

2.1. Meter and generative metrics. Meter is a regular pattern of rhythm, where the pattern may be associated with one or more of several factors: quantity, stress, syllable count, and tone. ${ }^{3}$ Quantitative meter is a pattern based on the arrangement of long and short syllables, as in Greek or Latin verse. Stress, or accentual meter, uses stressed syllables as the basic unit; Old English poetry, such as Beowulf, is an example of this. A third pattern is characterized by a fixed number of syllables; this pattern is typical of Romance versification, as in the twelve-syllable line of French Alexandrine verse. A fourth type results with the intersection of stress and syllable count, as in English iambic pentameter, which consists of a relatively fixed number of both stresses and syllables. ${ }^{4}$ Meter may also regulate verse on the basis of tone, as in the Chinese poetry examined in Chen (1979).

Generative meter takes as its basic premise that these styles reflect the unconscious use of language. One of the goals of generative metrics is to show the principles which underlie the rule-governed behavior of language in meter. This is the goal of this paper also.

Work in the theory of meter has focused on what constitutes the proper representation of stress for meter. There are three current theories which each argue for a different representation of stress: tree-based, grid-based, and Arboreal Grid-based. Much of the debate in generative meter has centered on the metrical representation of the words (that is, language) to

\footnotetext{
${ }^{3}$ The meter analyzed here is confined to stress. Impressionistically, the phonetic correlates of stress in Tohono O'odham are, to varying degrees, amplitude, pitch, and vowel duration. These correlates mean that it makes perfect sense to treat the meter as stress-based rather than to focus on the behavior of the specific correlates individually. Furthermore, stress is a category recognized and manipulated by native speakers. For example, in this paper, we see arguments for the phonological relevance of stress in Tohono O'odham meter based on the facts of "Vacuous" Reduplication. Additional evidence for the relevance of stress can be found in word stress (Fitzgerald 1997a), sentence prosody (Fitzgerald 1994), and from the destressing patterns of clitic groups (Fitzgerald 1997b). Further evidence can be found in the ability of native speakers to discriminate between stressed and unstressed syllables when asked to give rhythmic judgments (Fitzgerald 1997a). Looking exclusively at quantitative factors would be misleading, as stress in this language falls on odd syllables, with complications resulting from the morphological composition of the word. In no way is stress predictable on the basis of long and short syllables. Long vowels are restricted to initial, primary stressed syllables, so this supports my decision to focus on stress as a composite of these factors.

${ }^{4}$ There is also free verse, where neither syllables nor stress are regulated.
} 
which the constraints refer. This paper does not address that debate; rather, I am concerned with what the representation of the line must be for the proper treatment of the meter.

Next I give examples of grid and tree systems ${ }^{5}$ and explain some terminology, using English iambic pentameter as an example. Iambic pentameter is a line of poetry consisting of an abstract "template," with ten alternating strong and weak metrical positions. ${ }^{6}$ Not all lines realize this abstract template; a poet may have a line that exactly represents this with ten alternating stressless and stressed syllables. A poet's meter is constrained by the rules that dictate what type of material is allowed in the metrical positions.

First, there is the tree-based theory of meter found in Kiparsky (1977), which represents a line of iambic pentameter as below:

$\begin{array}{ccccc}\wedge & \wedge & \wedge & \wedge & \wedge \\ \text { W S } & \text { W S } & \text { W S } & \text { W S } & \text { W S }\end{array}$

Trees represent prominence relations between two metrical positions; ${ }^{7}$ the $\mathrm{S}$ position is more prominent than the $\mathrm{W}$. Additionally, trees also allow a representation of constituency; in (1), two metrical positions are each constituents of a single unit, the foot. More hierarchical structure may be added, such that two feet comprise a unit. ${ }^{8}$

A second representation of meter comes from the grid-based theory presented in Hayes $(1983 ; 1989)$. Grids indicate stressed syllables with an "X" and stressless syllables with a "."; the height of the X column over a stressed syllable indicates its relative level of stress. In this theory, the underlying meter of a line of iambic pentameter is a grid:

$$
\text { . X . X . X . X . X }
$$

Grids encode the level of stress and their local relations. Stress levels of syllables can only be compared where syllables are adjacent. The absence or presence of stress is also encoded, as is the stress level. However, the grid cannot represent constituency.

\footnotetext{
${ }^{5}$ Speaking generatively, that is. Actually, there is an additional theory proposed by Halle and Keyser (1971); see Kiparsky (1975) for arguments against it.

${ }^{6}$ Strong positions are those which generally contain stressed syllables, and weak positions typically hold unstressed syllables. Furthermore, restrictions are often stronger on weak positions, such that stressed syllables only appear in these positions under special circumstances.

${ }^{7}$ With the addition of more hierarchical structure, trees may indicate other prominence relations as well. See, for example, Kiparsky (1977) and Youmans (1989) for more discussion of these matters.

${ }^{8}$ Such structure is argued to be binary in Prince (1989).
} 
In this paper, I use a representation with both grids and trees for TO. This captures the fact that both prominence and constituency are important for the meter analyzed here. ${ }^{9}$

2.2. Stress in Tohono O'odham. ${ }^{10}$ Because this paper focuses on TO song metrics, a discussion of the stress system in TO is a prerequisite to examining the meter. For the purposes of this paper, I use only the primary stress in words. ${ }^{11}$ As established in various sources (Hale 1959, Saxton 1963, Hill and Zepeda 1992, and Fitzgerald 1997a), a primary stress falls on the first syllable of a stem. Secondary stress (indicated in $3 c, 3 g$, and $3 h$ ) falls on odd-numbered syllables in polymorphemic words, with additional complications in words with epenthesis or truncation (Fitzgerald 1997a). These patterns are illustrated in: ${ }^{12}$

$\begin{array}{lll} & \text { Surface Form } & \text { Gloss } \\ (3 a) & \text { má:c } & \text { 'knowing' } \\ (3 b) & \text { dá:dk } & \text { 'noses' } \\ (3 c) & \text { dádagșp } & \text { 'pressing down with fingers repeatedly' } \\ (3 d) & \text { tádai } & \text { 'roadrunner' } \\ (3 e) & \text { tátadài } & \text { 'roadrunners' } \\ (3 f) & \text { músigo } & \text { 'musician' } \\ (3 g) & \text { múmsigò } & \text { 'musicians' } \\ (3 h) & \text { s-músigò-dag } & \text { 'good at being a musician' }\end{array}$

The form in ( $3 a$ ) shows a monomorphemic form, which receives primary stress on the initial syllable. ${ }^{13}$ When words are reduplicated (as in $3 b, 3 c$, $3 e$, and $3 g$ ), primary stress falls on the prefixed reduplicant. If the word is polymorphemic and long enough, additional odd-numbered syllables are stressed (as in $3 e, 3 g$, and $3 h$ ). The form in ( $3 h)$ shows that the stative clitic,

\footnotetext{
${ }^{9}$ I leave aside the point of whether this favors representations of either the Bracketed Grid (Halle and Vergnaud 1987) or the Arboreal Grid (Hammond 1988; 1991).

${ }^{10}$ I employ the following abbreviations in this paper: PL plural; SG singular; REP reportative; AUX auxiliary; DET determiner; CONJ conjunction; LOC locative; STAT stative; DIST.PL distributive plural; CONT continuative; INIT initiative; and voc vocable.

${ }^{11}$ Primary stress is crucial for the characterization of the meter; secondary stress is not.

${ }^{12}$ The high vowels, $i$ and $u$, can each combine with another vowel to form a diphthong. Stress is marked on the monhigh vowel for these monosyllabic vowel-vowel sequences; for example, jiós 'God' or tátadài 'roadrunners'.

${ }^{13}$ Hill and Zepeda (1992) argue for demoraicization of unstressed syllables in certain environments. In (3), I give only sketchy derivations. For more detailed exposition of these arguments, see their paper. At this point, the reader only needs to know where primary stress occurs in TO words.
} 
$s$-, does not receive stress. Other clitics (e.g., third-person pl. object $h a-$ ) are also invisible to stress. These facts are further illustrated in:

\begin{tabular}{|c|c|c|}
\hline & Surface Form & Gloss \\
\hline$(4 a)$ & gógs & 'dog' \\
\hline$(4 b)$ & gógogs & 'dogs' \\
\hline$(4 c)$ & ñéid & 'seeing' \\
\hline$(4 d)$ & ha-ñéid & 'seeing (pl. object)' \\
\hline$(4 e)$ & ñéñeid & 'seeing (sg. object)' \\
\hline$(4 f)$ & ha-ñéñeid & 'seeing them (pl. object)' \\
\hline
\end{tabular}

2.3. The song corpus. This section gives background on the song corpus, the format in which I give the song data, and the specific phenomena of song lines. As we shall see in the following subsections, the phonology of these songs is rather complex. I try to give song lines in a format which makes the song phonology more accessible. Also, while works such as Bahr (1980; 1983), Chesky (1943), Haefer (1981), and Underhill (1938) have dealt with the music and songs of the O'odham, this is the first theoretical treatment of the meter of O'odham songs. The unanalyzed status of the corpus thus necessitates an exposition of what the songs look like before I present my analysis.

The song corpus used in this paper consists of eleven songs totaling seventy-eight lines. The songs used are traditional, where the description of traditional corresponds to a specific purpose and melodic content, and a specific type of origin. ${ }^{14}$ The songs are used for social or ceremonial purposes, such as traditional round dance songs or healing songs. Musical content is generally associated with a specific purpose; for instance, a certain type of dance requires a certain rhythm (much like a polka or waltz requires certain rhythms). Also, traditional songs are those which are either passed down from one generation of a singer to another or come to the singer via the inspiration of a dream. I began with the same methodology one would use in analyzing an English poet, such as Shakespeare. I scanned the lines (without considering the role played by the music) and marked syllables as stressed and unstressed, given that these facts are predictable in Tohono O'odham. This scansion is the foundation of the descriptive work for this paper. Note that this paper does not provide an analysis of the meter of the performance of these songs. Just as a poem may be declaimed differently than its scansion, so these songs may be sung differently than their scansions (see Bahr 1983, especially, for an analysis of the meter of performance). The

\footnotetext{
${ }^{14}$ My understanding of a definition of "traditional" comes primarily from Haefer (1977) and Ofelia Zepeda (personal communication).
} 
performance and the scansion are not always the same (for an interesting discussion on this temporal aspect of meter, see Oehrle 1989).

In this study, I analyze songs that all come from one source, Wallace (1981). ${ }^{15}$ Haefer (1977) discusses how variation in songs serves both as a way to discriminate between the quality of singers and as a means to create a new song. By using one source, I can isolate characteristics of a given singer or singers, much as Kiparsky (1977) and others have sorted various English poets into "dialects" of English poetry (i.e., Tudor poets, Milton, etc.) by the variation in their metrical rules.

The example below shows a song line, which I give in the format to be used in this paper. Each song line is noted by sonG; the example given differs from its notation in what I term CITATION form. CiTATION is used to gloss the TO song forms into TO dictionary forms. ${ }^{16}$ I then provide an English gloss of the O'odham forms in GLOSS. ${ }^{17}$ The final line, TRANSLATION, represents the song line in an approximate English translation. The format is:

$\begin{array}{lllll}\text { SONG } & \text { Wí-pis-mel } & \tilde{n} e ́-\tilde{n} e i & w a-\tilde{n} & \text { bíje-mi-da } \\ \text { CITATION } & \text { wipismel } & \tilde{n} e ́ \tilde{n} e ' i & a & \tilde{n} \text {-bíjemid } \\ \text { GLOSS } & \text { hummingbird } & \text { pl-song } & \text { AUX } & \text { 1sG-to surround }\end{array}$

TRANSLATION 'Hummingbird songs surround me'.

The notion of a line is referred to above and deserves some attention. Informally, I consider a line here to be set of one or more clauses, such that a group of lines constitutes a song. A line may also consist of just one phrase or may split a phrase between two lines. While clauses and phrases are important, they are not necessary to the definition of line. For our purposes, LINE is a string of words which corresponds to a musical phrase in the song.

There is an additional fact which suggests that the definition suffices in giving a characterization of line for TO songs. Lines in the songs may be repeated; one common pattern is $\mathrm{AABCBC}$, where the first line $(\mathrm{A})$ is repeated twice, the next new line (B) alternates with another new line $(C)$, and the BC sequence repeats. Given this independent argument in support of the line used here, an additional source of evidence favoring these lines can also be found from distributional evidence. There are no line-final stresses; as we shall see in $\mathbf{2 . 4}$, citation lines that end in stressed syllables do not correspond with song lines that end in stressed syllables. Rather, the

\footnotetext{
${ }^{15}$ The description of the songs in Wallace (1981) shows that they can be easily characterized under the auspices of a single system of meter.

${ }^{16}$ Citation forms are confirmed in Mathiot (1973) and Saxton, Saxton, and Enos (1989). They appear here in the official orthography, with primary stress added.

${ }^{17}$ Ofelia Zepeda, a native speaker of O'odham and a linguist, was an invaluable source of help in both the TO and English glossing of the songs, and I take yet another opportunity to thank her.
} 
corresponding song lines "vacuously" reduplicate the line-final monosyllable, which results in a song line that does not end in a stressed syllable.

2.4. Reduplication. In this section, I examine reduplication within the songs. Reduplication is used morphologically in TO to indicate the plurality of nouns, verbs, and some postpositions. Of the forty-eight instances of reduplication found in the song corpus, only twenty are plural reduplications. This means that there are twenty-eight reduplicated forms which do not have an associated plural meaning. Here, I first contrast morphological and nonmorphological (or Vacuous) reduplication. Then I present data which show that Vacuous Reduplication is motivated by stress considerations. Finally, I give the generalizations of this section, which lay the groundwork for the analysis of meter presented later.

As mentioned above, the songs do contain examples of straightforward, morphological reduplication. An example of this appears in (6). The singular form gídwul 'swallow' reduplicates as gígidwul 'swallows' (the reduplicant is underlined).

$\begin{array}{llll}\text { E-da } & g & \text { gígi-dwul-e } & \text { néi-o-pa-ha } \\ \text { eda } & g & \text { gígidwul } & \text { né'iopa } \text { VOC }^{18} \\ \text { while } & \text { DET } & \text { PL-swallow } & \text { PL-to fly }\end{array}$

'While the swallows flying ...'

However, there are also song lines which contain reduplication without a corresponding semantic change. That is, singular nouns and verbs reduplicate in song lines, where they would not reduplicate in citation lines. This can be seen in the examples below, with prefixal reduplicants underlined. ${ }^{19}$

(7a) Vacuous Reduplication line-initially

$\begin{array}{cllll}\text { Wá-wai } & \text { gí-wa-lige } & \text { we-co } & \text { ná-ha-gio } & k c \\ \text { Wáw } & \text { gíwulk } & \text { weco } & \text { náhagio } & k c \\ \text { rock } & \text { Cinched below } & \text { mouse } & \text { CONJ } \\ \text { in } & \text { mém-ě-li-hi-me } & & \\ \text { in } & \text { mémelihim } & & \\ \text { LOC } & \text { to run to repeatedly } & & \end{array}$

'The mouse runs around there below Cinched Rock'.

\footnotetext{
${ }^{18}$ Vocables are contentless syllables, as in the final syllable, -ha, in the song form ñéi-opa-ha. Vocables (glossed as VOC) consist of adding an entire syllable, not just a vowel, at the end of a word. While I do not deal with vocables here, Hymes (1981) and Hinton (1980) give evidence that these "nonsense syllables" have specific function within a text. Vocables do seem able to appear both line-medially and line-finally, and there are examples which have two vocables next to each other. Future research may reveal the role played by vocables in these songs.

${ }^{19} \mathrm{I}$ rely on the helpful intuitions of Ofelia Zepeda for where reduplication is vacuous and where syllables are meaningless or "vocables."
} 
(7b) Vacuous Reduplication line-finally

$\begin{array}{lllll}\text { Jiós } & \text { oi } & k a ́ \text {-wu-li-ki } & \text { yam-e } & \text { ké-he-ka } \\ \text { Jiós } & \text { 'o } & i \text {-gáwulk } & \text { 'am } & \text { ké: } k \\ \text { God } & \text { AUX } & \text { INIT-to differ } & \text { LOC } & \text { to stand }\end{array}$

'God starts to differ standing there'.

(7c) Multiple instances of Vacuous Reduplication within a line

$\begin{array}{llll}o i & n a & \text { só-so } & k \text { ú:- } k u:-\eta p e \\ o i & n a & \text { són } & k u ́: g \\ \text { soon } & \text { perhaps } & \text { the beginning } & \text { the end }\end{array}$

'soon perhaps the beginning, the end'

The first example in (7a) shows two things: (1) Vacuous Reduplication may occur line-initially. (2) Extra vowels or syllables (or both) may also occur where there is Vacuous Reduplication. We can see the first pattern in (7a), where the underlined word wáw 'beginning' falls in initial position and reduplicates. The line itself also shows the second point with the word mémelihim 'to run to repeatedly', which ends in the song line with an extra vowel, which adds a syllable to the length of the word.

Two forms, ké-he-ka in (7b) and kú:-ku:-ne in (7c), also show that extra vowels may occur with Vacuous Reduplication. The line-final vowel in $(7 b)$, $-a$, may occur in speech, while the extra line-final vowel of $(7 c),-e$, does not. These forms also show that Vacuous Reduplication may occur linefinally. In addition, the two reduplicated forms in $(7 c)$ also show that a given line may have more than one occurrence of this type of reduplication.

At this point, let me also point out the generalizations of Vacuous Reduplication, as suggested by the data in (7). First, only monosyllabic citation forms (wáw, ké:k, són, and kú:g) correspond with the reduplicated song forms. Second, these forms are all either nouns or verbs and, hence, bear lexical stress. ${ }^{21}$ Third, citation lines show that words that undergo Vacuous Reduplication either precede a stressed syllable (as each precedes either a verb or noun) or occur line-finally (or both, as in 7c). The crucial point here is that all words which reduplicate are stressed monosyllabic words which do not precede an unstressed syllable. These generalizations become

${ }^{20}$ Donald Bahr suggests that perhaps this word is actually the noun, káwulk 'hill'. One bit of evidence supporting the choice of gáwulk 'to differ' is the presence of the verb marker, $i$, INIT, manifested in the song line together with the vowel of the auxiliary.

${ }^{21}$ To simplify things here, I exclude postpositions which are stressed. Fitzgerald (1993) shows that these postpositions, when monosyllabic, behave the same way as words with lexical stress, because both types of words reduplicate preceding a stressed syllable. In certain cases, the postposition appears to be receiving stress from emphatic use. Both Kiparsky (1977) and Hayes (1983) show how contrastive stress or emphasis may change the normal scansion for stressed syllables. 
clearer in (8) below, where I present a breakdown of the conditions where Vacuous Reduplication occurs:

(8) Distributional facts for citation lines that allow Vacuous Reduplication

$\begin{array}{lccc}\text { Category } & \begin{array}{c}\text { Length } \\ \text { in } \sigma\end{array} & \begin{array}{c}\text { Precedes } \\ \text { Stressed } \sigma\end{array} & \begin{array}{c}\text { Occurs } \\ \text { Line-Finally }\end{array} \\ \text { Nouns } & 1 & 6 & 7 \\ \text { Verbs } & 1 & 2 & 5\end{array}$

The hypothesis, then, is that Vacuous Reduplication is predictable based on the stress pattern of the citation lines. This is borne out when we consider whether there are any song lines that allow stressed syllables to be adjacent or occur line-finally. The contrast obtains, as the corpus has no examples of song lines with either adjacent stresses or line-final stresses for monosyllables. There are, however, examples of polysyllabic words with stress which appear adjacent to a stressed syllable or line-finally. These cases do not occur with Vacuous Reduplication (unless they have a phonological shape, as does jewed 'earth', which allows scansion as monosyllables) ${ }^{22}$ In (9), I give these examples (only Vacuous Reduplication is underlined).

(9a) $s$

$\begin{array}{ll}S & w a \\ S & o a \\ \text { REP } & \text { as mentioned }\end{array}$

'Damply it emerges'.

(9b)

$\begin{array}{llll}\text { Áw-pa } & \text { hió-sig } & \text { ga-pe } & \text { hí-me-na-ha } \\ \text { áuppa } & \text { hiósig } & \text { ga vOC } & \text { híma } \text { VOC VOC } \\ \text { cottonwood } & \text { blossom } & \text { over there } & \text { to walk }\end{array}$

'Over there, cottonwood blossoms pass by'.

(9c)

$\begin{array}{lll}\text { Pí-si-ne } & \text { mó-ka-me } & \text { jé-je-wen } \\ \text { písin } & \text { móo-kam } & \text { jéwed } \\ \text { bison } & \text { head-one with } & \text { earth }\end{array}$

'Bison Head' (place)

The song lines in $(9 a)$ and $(9 b)$ allow two lexically stressed words to appear adjacent to each other, without Vacuous Reduplication. Note that

${ }^{22}$ Two disyllabic words always reduplicate line-finally: dóag 'mountain' and jéwed 'earth'. The intuition here is that they are treated as monosyllables by the meter, much as in English heaven may be scanned as monosyllabic heav'n; in fact, their medial onsets do allow them to be pronounced as monosyllables in less careful speech. However, in line-medial positions, they do not always pattern with monosyllables. 
these examples do not have adjacent stresses, as in the previous examples from (7), as the underlined forms are not monosyllables. This means that there are intervening unstressed syllables.

The final two stressed words in $(9 a)$ and $(9 b)$ show that such polysyllabic forms also appear line-finally. Again, the forms do not reduplicate. However, unlike the forms from (7), the stressed syllables of these words do not appear as the final syllable of the line.

Based on these two sets of facts (the first showing where Vacuous Reduplication does occur, the second showing where it does not), I propose that Vacuous Reduplication is motivated by the metrical system of the song.

In order to view the metrical nature of Vacuous Reduplication, I give the song lines from (7) again below in (10). In this example, I show both citation and song lines in the grid-based theory of meter used by Hayes (1983; 1989). An examination of these forms shows that Vacuous Reduplication only occurs wherever either two stresses are adjacent $(\underline{X X})$ or wherever a stress would fall line-finally at the rightmost edge of a line $(\underline{\underline{X}})$.

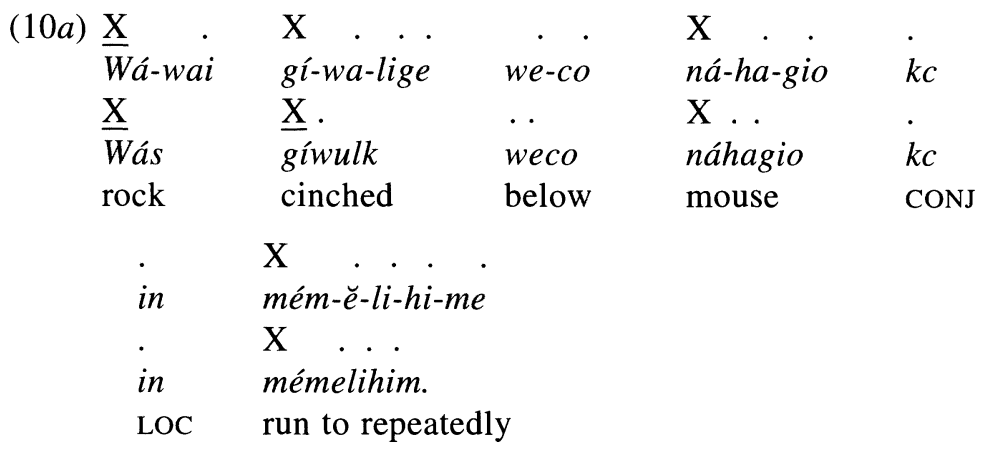

'The mouse runs around there below Cinched Rock'.

$(10 b)$

\begin{tabular}{|c|c|c|c|c|c|}
\hline $\mathrm{X}$ & & & $\mathrm{X}$ & & \\
\hline Jióș & $o i$ & & $k a ́-w u-l i-k i$ & yam-e & $\underline{\overline{k e}}-h e-k a$ \\
\hline$X$ & . & . & $\mathrm{X}$ & & $\underline{X}$ \\
\hline Jiós & 'o & $i$ - & gáwulk & 'am & $\overline{\overline{k e ́}}: k$ \\
\hline God & AUX & & INIT-to differ & LOC & to stand \\
\hline
\end{tabular}

'God starts to differ standing there'.

$(10 c)$

$\begin{array}{lll}\text { Oi } & \text { na } & \underline{\mathrm{X}} . \\ \cdot & \cdot & \underline{\mathrm{X}}-s \underline{0} \\ \text { oi } & n a & \underline{\text { són }} \\ \text { soon } & \text { perhaps } & \text { the beginning } \\ \text { 'soon } & \text { perhaps the beginning, the end' }\end{array}$


By aligning the song and citation lines to the metrical grid, we see even more clearly that wherever citation lines appear with adjacent stresses or a line-final stress, the song line appears with the leftmost word of two stressed words or the final word in a line vacuously reduplicated. These observations suggest two conclusions: (1) Stress clash and line-final stresses are impermissible in the song meter and (2) Vacuous Reduplication resolves these stress violations where they would otherwise occur, given the corresponding citation line.

In addition to Vacuous Reduplication, song lines may include additional vowels. Let me now cover the interaction of the effects of Vacuous Reduplication with these vowels to show that these vowels are irrelevant to Vacuous Reduplication. Below I compare examples of Vacuous Reduplication in the song and citation lines, and in hypothetical line constructions both with and without extra vowels. The examples in $(11 b)$ and (11c) show that extra vowels may also appear in the same environment (where two stresses are adjacent or where a stress is line-final) where Vacuous Reduplication occurs. Adjacent stresses are single-underlined and line-final stresses are double-underlined.

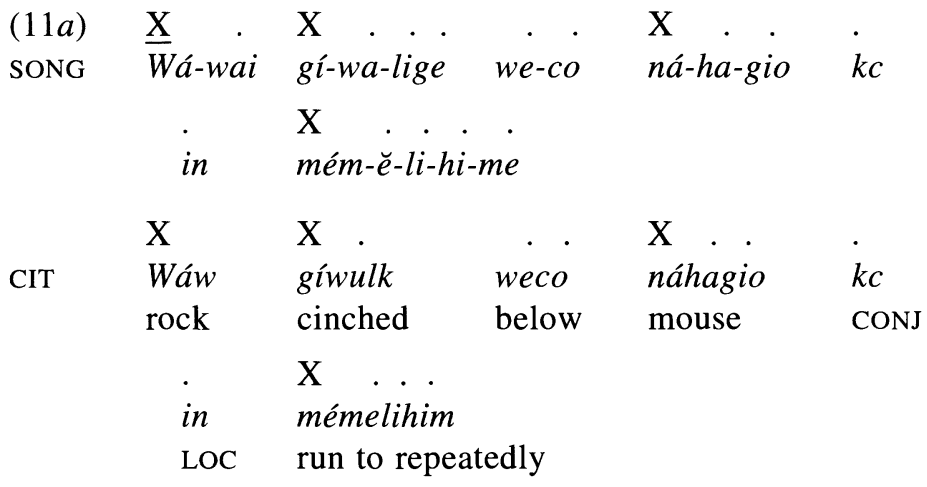

'The mouse runs around there below Cinched Rock'.

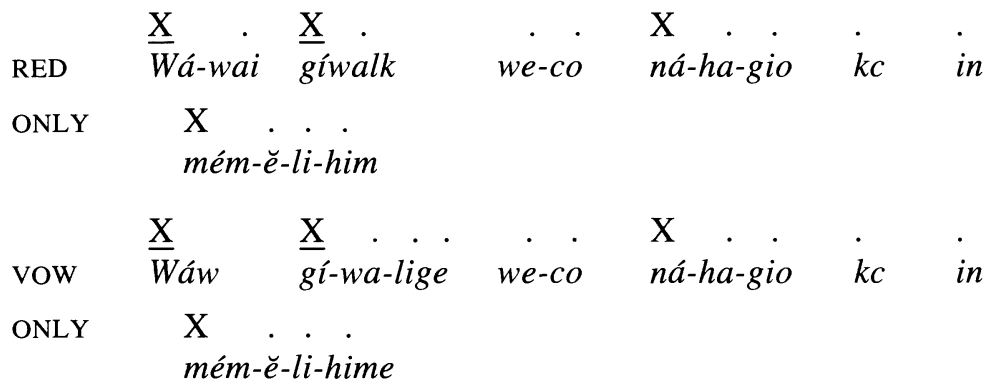


$\begin{array}{lll}(11 b) & \mathrm{X} \\ \text { SONG } & \text { Jiós } & \end{array}$

$\begin{array}{lll} & \mathrm{X} & \\ \mathrm{CIT} & \text { Jiós } & \text { 'o } \\ & \text { God } & \text { AUX }\end{array}$

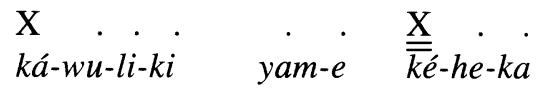

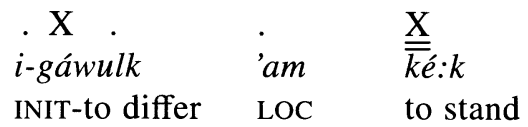

'God starts to differ standing there'.

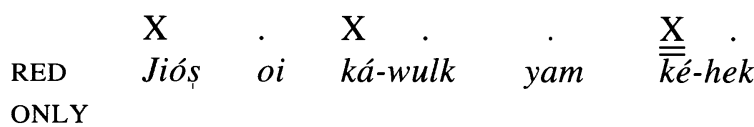

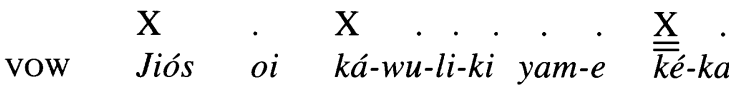

ONLY

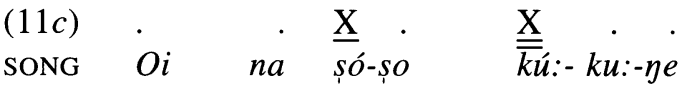

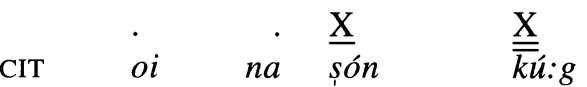

soon perhapsthe beginningthe end

'soon perhaps the beginning, the end'

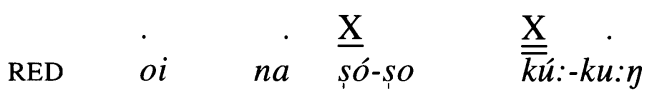

ONLY

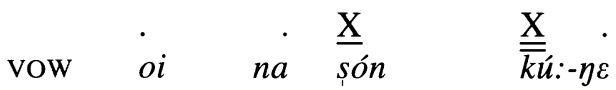

ONLY

The first two examples show that extra vowels and Vacuous Reduplication may occur in the same environment, that is, wherever stresses are adjacent or line-final. However, the forms in (11a) and (11c) are critical in showing that the extra vowels cannot be predicted on this basis for this environment, because these vowels surface in other environments in these same lines. However, Vacuous Reduplication only appears in the environment of line-final or adjacent stresses. Furthermore, there are cases where extra vowels never surface in this environment. In (11c) són reduplicates adjacent to another stress, and without surfacing with extra vowels. This indicates that these vowels must be absent when Vacuous Reduplication 
applies, or else the triggering environment would be removed and Vacuous Reduplication could not apply. The extra vowels thus play no role in this interaction between meter and morphology.

2.5. Characteristics of song lines. In this section, I cover three characteristics of song lines. First, I discuss the length of song lines and show that there is a flexible number of syllables. Second, I show further flexibility in the number of stresses per line. Third, I discuss two important metrical positions of TO song lines, second and final, to show that distributional facts reveal these two positions are never filled with stressed syllables. These facts indicate how TO song lines are rigid.

This section is important for several reasons. First, it will help in determining how to characterize the underlying metrical pattern of TO song meter. Second, recall from the discussion of meter above that rhythmic patternings are derived from quantity, stress, or syllables. Here the discussion shows that it is difficult to place TO song meter in one of these categories.

First, let us examine line length. Line length in these songs is rather variable; songs may use lines of anywhere from seven to nineteen syllables, as seen below:

$\begin{array}{clllll}\text { (12a) } S & \text { 'a-me } & g & \text { yód-ha-me } & \text { yu huwi. } & \begin{array}{l}\text { Ó-'od-ha-me } \\ \text { íodham }\end{array} \\ S & \text { 'am } & g & \text { óodham } & \text { i-huwi. } \\ \text { over here. } & \text { people } \\ \text { REP LOC } & \text { DET people } & & \\ \text { we-wem-e } & \text { jú-ne-kam } & & \\ \text { wem } & \text { júñam } & & \\ \text { with } & \text { to exist-one } & & \end{array}$

'They say over here are the People. With the People is the one who was'.

\begin{tabular}{|c|c|c|c|c|}
\hline 2b) $\begin{array}{l}o i \\
\quad o i \\
\text { soon }\end{array}$ & $\begin{array}{l}\text { na } \\
\text { na } \\
\text { perhaps }\end{array}$ & $\begin{array}{l}\text { só-so } \\
\text { són } \\
\text { the beginning }\end{array}$ & $\begin{array}{l}k u ́:-k \\
k u ́: g \\
\text { the } \mathrm{e}\end{array}$ & $:-\eta e$ \\
\hline oo & perhaps the & ginning, & & \\
\hline 2c) $S$ & $w a$ & $s$-wá- & $-m e$ & wú-wa-ke \\
\hline 9 & & s-wápusi & & wúwhag \\
\hline REP & as mention & STAT-PL- & amply & to emerge \\
\hline
\end{tabular}

'There, they say, damply they emerge'.

The song line in (12a) has nineteen syllables, $(12 b)$ has seven syllables, and the third example $(12 c)$ is ten syllables.

Songs do not individually cluster about a certain line length either, as each song may contain lines of varying lengths. This in itself is not unusual, as it is characteristic of Old English verse, such as Beowulf (cf. Cable 1974; 1991 and Russom 1987). However, the variability in OE meter can be re- 
Syllables per Song Line

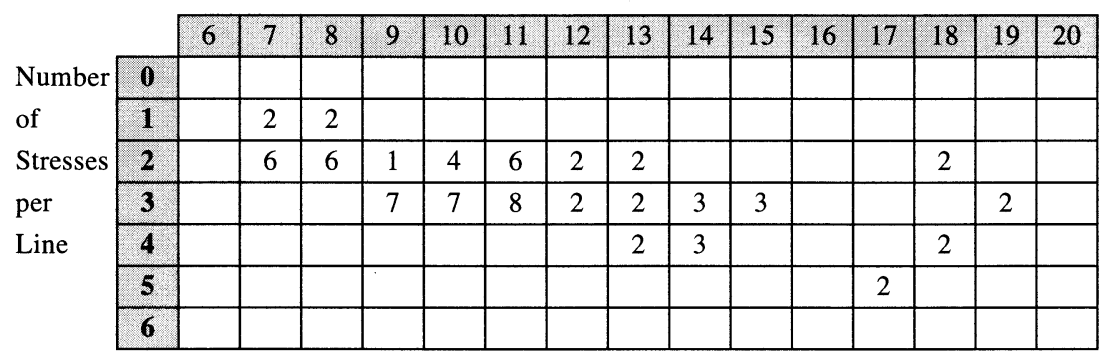

FIG. 1.-Distribution of song lines, according to line length and number of stresses.

duced by factoring out resolution..$^{23}$ This is not true of TO meter. While the statistics show how long (or short) lines may be, there is little to tell what the limits to the lower and upper reaches actually are. Therefore, I suggest that the length of a song line is unconstrained.

The number of stresses per line, and where they appear, is also an important factor in characterizing the flexible nature of the line. The number of stresses per line appears to cluster around three, although like line length, these numbers are relatively flexible. A given line may contain anywhere from one to five. The actual numbers for the distribution are given in (13):

(13) Distribution of lines according to number of stresses

$\begin{array}{lccccccc}\text { STRESS: } & 0 & 1 & 2 & 3 & 4 & 5 & 6 \\ \text { NUMBER OF LINES: } & 0 & 4 & 28 & 33 & 7 & 2 & 0\end{array}$

These numbers show that most song lines contain either two or three stresses. In figure 1, I have combined information to show the interaction of number of stresses per line with number of syllables.

Figure 1 shows that as the number of stresses increases, so does the number of syllables. One stress per line corresponds with song lines of the smallest attested lengths, seven and eight syllables. These lengths have more lines with two stresses per line; at two stresses per line, longer lines also start to appear, with line lengths of nine to thirteen and eighteen attested at this point. These line lengths (nine to eleven syllables) become more common with three stresses per line; in fact, they are the lower cutoff point for this range. At three stresses per line, lines of twelve to fifteen syllables and nineteen syllables begin to appear. At four stresses per line, the lower cutoff becomes thirteen syllables in length; fourteen and eighteen syllable lines also

\footnotetext{
${ }^{23}$ Resolution is the process "whereby a short stressed syllable and the following syllable, long or short, are scanned as one" (Cable 1974:7).
} 


\begin{tabular}{|c|c|c|c|c|c|c|c|}
\hline First & Second & Third & Fourth & Other & Antepenult & Penult & Final \\
\hline 34 & 0 & 18 & 35 & 65 & 39 & 9 & 0 \\
\hline
\end{tabular}

FIG. 2.-Position of stresses within a song line.

\begin{tabular}{|c|c|c|c|c|c|c|c|}
\hline First & Second & Third & Fourth & Other & Antepenult & Penult & Final \\
\hline 32 & 7 & 15 & 41 & 16 & 28 & 34 & 5 \\
\hline
\end{tabular}

FIG. 3.-Position of stresses within a citation line.

appear with four stresses per line. Finally, five stresses per line, the highest attested number of stresses, appear in seventeen syllable lines.

The crucial generalization here has been with respect to the nature of a song line; it cannot be characterized consistently in terms of length in syllables or number of stresses. It does appear that as the number of stresses per line increases, so does that of the syllables. However, there is no evidence for there being restrictions on either, except for the restrictions on where stresses can appear in a line.

Now let us explore the distributional facts of where these stresses may appear in a line. As stated above, the second and final metrical positions of a given line are never occupied by stressed syllables. The distributional facts are most easily revealed in figure 2 , which gives the distribution of stresses for the first four metrical positions in a line, the final three in a line, and all other (medial) positions. The restriction on these two positions does not hold with a citation line. Figure 3 shows that stresses appear in all positions in a (citation) line.

A comparison of figures 1-3 suggests that the songs restrict the second and final position. The latter restriction is noted as typical of trochaic verse, according to Attridge (1982). The restriction on second position in song lines, when viewed in conjunction with the high number of stresses which appear in the initial metrical position of a line, suggests that song lines begin with a trochaic sequence ( $\mathrm{S} \mathrm{W}$ ) or two lexically unstressed syllables (W W), but never begin with an iambic sequence (W S). These elements argue for a trochaic meter, at least at the line's edges.

It is important to note one further point: trochaic meter typically places stresses in the $\mathrm{S}$ positions, which are odd, and avoids placing them in $\mathrm{W}$ positions, the even ones. While this characterization is true of the leftmost W position (it is always even and never has stress), the same is not true of the rightmost position (the final metrical position of a song line may be either odd or even and never has stress). I postpone further discussion of this until I propose an analysis for TO song meter. 
The absence of stressed syllables in the second and final positions of song lines (fig. 2) becomes even more intriguing when we note that these positions are occupied in citation lines (fig. 3). Nevertheless, the low number of stresses even in citation lines suggests that avoiding stress in these positions plays a role in structuring the line, even at the citation level. I compare these facts in (14), where I compare song and citation lines in the grid.

(14a) Stress appears in second position in citation line but not in song line

$\begin{array}{lll}\mathrm{X} & \mathrm{X} & \mathrm{X} \\ \text { Wá-wai } & \underline{\overline{g i} \text {-wu-lik-e }} & \text { nó-no-hà } \\ \mathrm{X} & \mathrm{X} \cdot & \mathrm{X} \\ \text { Wáw } & \text { gíwulk } & \text { dóag } \\ \text { rock } & \text { constricted } & \text { mountain }\end{array}$

'Constricted Rock Mountain'

(14b) Stress appears in final position in a citation line but not in a song line

\begin{tabular}{|c|c|c|c|c|}
\hline$X$ & & & & \\
\hline Jiós & $o i$ & $k a ́-w u-l i-k i$ & yam-e & $\underline{\bar{k} e}-h e-k a$ \\
\hline $\mathrm{X}$ & & $\mathrm{X}$ & & $\underline{X}$ \\
\hline Jiós & 'o & i-gáwulk & 'am & $\overline{\overline{k e}}: k$ \\
\hline jod & AUX & INIT-to differ & LOC & to stand \\
\hline
\end{tabular}

'God starts to differ standing there'.

The contrast in (14) between the song lines and the citation lines shows that stresses are prohibited in the second and final metrical positions of a line. The line in $(14 b)$ also shows that the morphology of TO, which uses reduplication to indicate the plurality of nouns and verbs, may also be employed in order to avoid placing stresses in final position. I showed above that the Vacuous Reduplication in these lines is used systematically to prevent stresses from being adjacent to each other or from appearing linefinally. The example in (14a), which triggers reduplication by virtue of the two adjacent stresses, does show a stress in second position in the citation line. ${ }^{24}$ Interestingly, stressed syllables which occupy second position in citation lines also appear adjacent to other stresses, violating two restrictions on the meter. This is resolved by Vacuous Reduplication in the song line. As the reduplication adds another syllable, the stressed second syllable moves into the third metrical position.

\footnotetext{
${ }^{24}$ An alternate account of the form wáwai 'cliff' is that the form reflects an archaic singular, rather than reduplication (thanks to Jane Hill for noting this). Interestingly, the form wáw also appears once, at the beginning of one song, as wawawai. The scarcity of other forms like this makes it impossible to generalize. I do note here that wáwai may reflect a preserved form; this does not change the fact that stressed syllables do not appear in the second metrical position. I assume here that wáw is the citation form and wáwai a form reflecting Vacuous Reduplication.
} 
Finally, if we look at the line-final stress which triggers reduplication, we see that both conditions (line-final and adjacent stresses) may appear in one line. This can be seen in (15).

(15)

\begin{tabular}{|c|c|c|c|}
\hline & & $X$ & $X$ \\
\hline$o i$ & $n a$ & $\frac{s o ́}{\overline{\mathrm{X}}}-s o$ & $\begin{array}{l}k u ́:-k u:-1 \\
\mathrm{X}\end{array}$ \\
\hline $\begin{array}{l}o i \\
\text { soon }\end{array}$ & $\begin{array}{l}\text { na } \\
\text { perhaps }\end{array}$ & $\begin{array}{l}\text { són } \\
\text { the beginning }\end{array}$ & $\begin{array}{l}k u ́: g \\
\text { the end }\end{array}$ \\
\hline
\end{tabular}

In this section, I have made several points regarding the absence of stressed syllables in the second and final metrical positions in a song. Specifically, I have shown that (1) distributional facts of song lines reveal that these positions never appear with stressed syllables; (2) citation lines may appear with stressed syllables in these positions; and (3) Vacuous Reduplication strategically allows a stressed final syllable to appear nonfinally, as well as helping to avoid the placement of such syllables in second position. I conclude this section having shown that because the morphology may be manipulated to avoid the appearance of stresses in second and final positions within a song line, it is the case that these positions are systematically devoid of stressed syllables. That is, it is not a coincidence, but rather reflects a metrical strategy of avoiding these two positions in the meter.

3. An analysis of Tohono O'odham song meter. In this section I present an analysis of the TO song meter. The crucial generalizations this analysis must accommodate are these:

(16) The descriptive generalizations of Tohono O'odham song meter

A. The second and final metrical positions are never filled with stressed syllables because Vacuous Reduplication is used to prevent stresses from appearing in these positions.

$B$. The song's meter is also restrictive in that it prohibits adjacent stresses. Adjacent stresses trigger reduplication of the leftmost element to create an intervening unstressed syllable.

$C$. Lines are flexible in number of stresses and syllables.

In this section I first present a proposal which covers the first set of generalizations. Then I propose a treatment of the second set of generalizations; following this, I discuss the integration and interaction of both constraints.

3.1. The Edge Constraint. There are three sets of related facts which must be dealt with adequately in this section: the restriction on both the second and final metrical positions; the strictness of both edges; and the 
fact that the final position may be either odd or even. In fact, all noninitial stresses may occur in either odd or even positions. In 2 we saw the edge effects robustly. Here I show the third characteristic as well.

The restriction on stress in these two positions suggests that the meter is trochaic ( $\mathrm{S} \mathrm{W}) ; \mathrm{S}$ positions are odd and $\mathrm{W}$ positions are even within a line. In the examples below, I show one unfortunate consequence of proposing that the meter is trochaic; by aligning each syllable in the song line with alternating odd and even positions, I show that all noninitial stresses may fall in odd or even positions, focusing here on the final position. The examples are given below.

(17a) Song line ending in odd (S)

$\mathrm{X} \cdot \mathrm{X} \cdot \mathrm{X}$..

SONG pí-si-ne mó-ka-me jé-je-wen

S W S W S W S W $\underline{\mathrm{S}}$

písin móo-kam jéwed

bison head-one earth

'Bison Head' (place)

(17b) Song line ending in even (W)

\begin{tabular}{|c|c|c|c|c|}
\hline \multirow[b]{2}{*}{ SONG } & \multirow{3}{*}{$\begin{array}{l}S \\
S \\
S\end{array}$} & \multirow{2}{*}{ wa } & $\mathrm{X}$ & \multirow{2}{*}{$\begin{array}{l}\mathrm{X} \\
w u ́-w a-\underline{k e}\end{array}$} \\
\hline & & & s-wá-pu-si-me & \\
\hline & & W & S W S W S & W S W \\
\hline & $\underset{S}{S}$ & $o a$ & s-wápusim & wúwhag \\
\hline & REP & as mentioned & STAT-PL-damply & to emerge \\
\hline
\end{tabular}

'Damply they emerge'.

(17c) Song line ending in even (W)

$\begin{array}{llll} & \mathrm{X} & \mathrm{X} & \mathrm{X} \cdot \\ \text { SONG } & \text { Nó-lig-kam-e } & \text { jé-wen-e } & \text { ká-ha-ce } \\ \mathrm{S} \mathrm{W} & \mathrm{S} \mathrm{W} & \mathrm{S} \mathrm{W} \mathrm{S} & \mathrm{W} \mathrm{S} \underline{\mathrm{W}} \\ \text { Nóligk } \quad \text { 'am } & \text { jéwed } & \text { ká:c } \\ \text { to turn } \quad \text { LOC } & \text { earth } & \text { to lie over an area }\end{array}$

'Noligk lies there on earth'.

(17d) Song line ending in odd (S):

\begin{tabular}{|c|c|c|c|c|}
\hline & & & & \\
\hline & $X$ & $X$ & & $X$ \\
\hline SONG & Wí-pis-mel & $\tilde{n} e ́-\tilde{n} e i$ & $w a-\tilde{n}$ & bi-je-mi- $\underline{d a}$ \\
\hline & S W S & W S & W S & W S W $\underline{S}$ \\
\hline & wipismel & $\tilde{n} e ́ n ̃ e ’ i$ & oa $\tilde{n}-$ & bíjemid \\
\hline & hummingbird & PL-song & as mentioned & 1sG-to surround \\
\hline
\end{tabular}


These four examples show two things: (1) that lines do not consistently end in either odd or even syllables, and (2) if song lines are characterized as trochaic, as above, approximately half of all stresses appear in Weak positions. Six of the eleven stresses appear in Weak position. This observation is important, although at this point I wish to postpone discussion of it because it does not fit into the current discussion of edge effects. The relevant examples, however, show that the fluidity of the line length makes it difficult to characterize the meter as underlyingly trochaic, if such meter is viewed merely as alternating strong and weak positions as in Hayes (1983; 1989).

The current problem is this: how do we characterize the fact that stresses are restricted from these two metrical positions (second and final) on edges of song lines? Is it possible to characterize, in one way, the similar behavior of these two positions (both on the edge, both typically iambic and hence weak), despite the dissimilarities (one is always even, while the other may be even or odd)? Or can it only be characterized as two separate restrictions?

I suggest that it is possible to make a unified characterization of the behavior of these two positions, and that this characterization is imperative in view of the fluidity of line length in TO song meter. My proposal is quite simple: (1) Trochaic feet are built on each edge of a song line. (2) Stresses are prohibited in the Weak positions of these feet. I have formalized the two parts of this proposal as components of the Edge Constraint in (18):

(18) Edge Constraint

(18a) All metrical song lines minimally begin and end with a trochaic foot.

$(18 b) *$ Foot

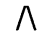

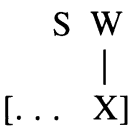

What does each part of (18) do? The statement in (18a) stipulates that the left and right edges of song lines must consist of trochaic feet. Only feet allow the reference to the second and final metrical positions; no other construction ensures reference to the restrictions on these positions. The construction in $(18 b)$ prohibits stress in the Weak position of a foot. The Edge Constraint as formulated will only apply to two metrical positions (second, final) because there are no other feet in the meter to which $(18 b)$ can apply (at this point, I argue for the presence of feet only at line edges). 
Especially striking is the formal reference to the Foot. Without a binary foot, as in $(18 b)$, we cannot unify the reference to both positions. In fact, without a foot, it is otherwise impossible to refer to the second position in meter. $^{25}$

The formalization in (18) accomplishes several goals: (1) It accommodates both edge restrictions. (2) Edges are restricted without directly specifying the position but instead by using a linguistic unit, the foot. (3) It formalizes only a prohibition on stresses in edgemost W's; recall that the evidence of (17) showed that stresses appear in other W positions. At this point in the analysis, the constraint in (18) suggests that there are only two relevant $\mathrm{W}$ positions which are evaluated. This can be seen in (19), where I give the song lines in (17) under the Edge Constraint:

(19a) No violation of the Edge Constraint in a song line ending in odd

\begin{tabular}{|c|c|c|c|}
\hline \multicolumn{2}{|c|}{ Foot } & & Foot \\
\hline & 11 & & I \\
\hline & S & & W \\
\hline & {$[\mathrm{X}$.} & & X \\
\hline NG & $\begin{array}{l}\text { pi-si-ne } \\
\text { písin } \\
\text { bison }\end{array}$ & $\begin{array}{l}\text { mó-ka-me } \\
\text { móo-kam } \\
\text { head-one }\end{array}$ & $\begin{array}{l}\text { jé-je-wen } \\
\text { jéwed } \\
\text { earth }\end{array}$ \\
\hline
\end{tabular}

'Bison Head' (place)

(19b) No violation of the Edge Constraint in a song line ending in even Foot

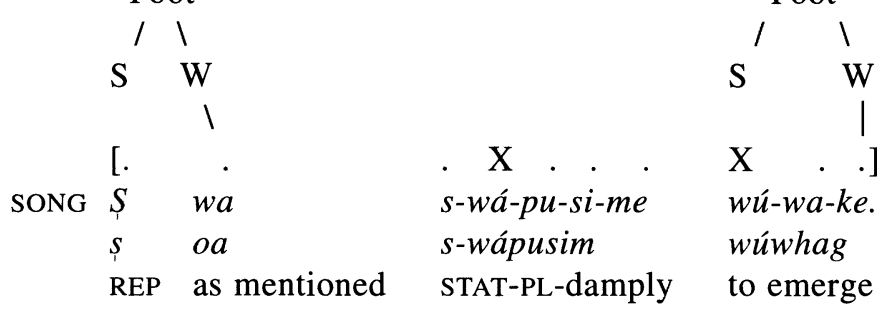

'Damply they emerge'.

\footnotetext{
${ }^{25}$ The only other possible way to restrict these positions would be if we characterize the line as: [S W ...W], prohibiting stress in all $\mathrm{W}$ positions. This characterization would be possible if there were only edge effects in TO song meter and the middles of lines were completely unrestricted. However, the restriction on adjacent stresses as a condition for Vacuous Reduplication suggests that TO song meter consists of more than just edge restrictions. I show this in more detail in $\mathbf{3 . 2}$.
} 
(19c) No violation of the Edge Constraint in a song line ending in even

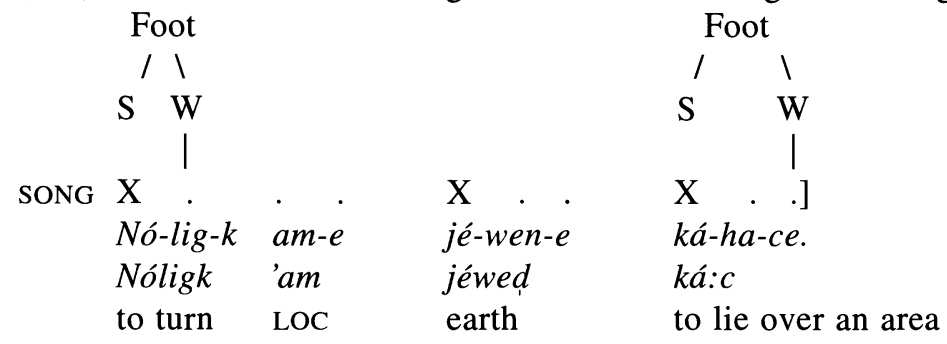

'Noligk lies there on earth'.

(19d) No violation of the Edge Constraint in a song line ending in odd Foot

/ 1<smiles>[X][W]#[W]</smiles>

SONG Wí-pis-mel

wípismel

hummingbird
$\mathrm{X}$

$\tilde{n} e ́-\tilde{n} e$ ñéñe'i $a \quad \tilde{n}$ -

PL-song AUX

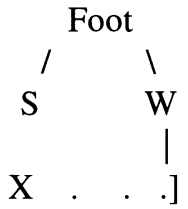

bí-je-mi-da.

bíjemid

1sG-to surround

'Hummingbird songs surround me'.

The formalization of the Edge Constraint in (18) successfully captures the generalizations of the data and characterizes song lines.

A similar observation is true with respect to the right edge, because a line with final stress, which would otherwise violate the Edge Constraint, instead corresponds with Vacuous Reduplication. The correspondence between the Edge Constraint and line-final cases of Vacuous Reduplication can be seen in (20), where I give each line in song line form and citation line form (final stresses are underlined, with violations double underlined):
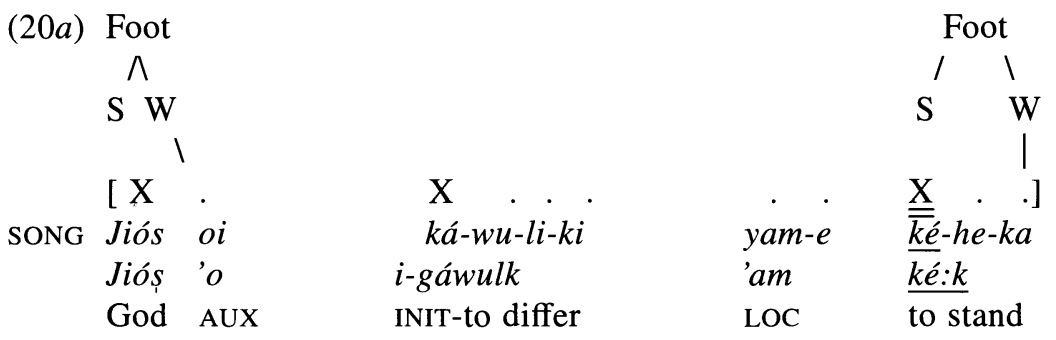

'God starts to differ standing there'. 


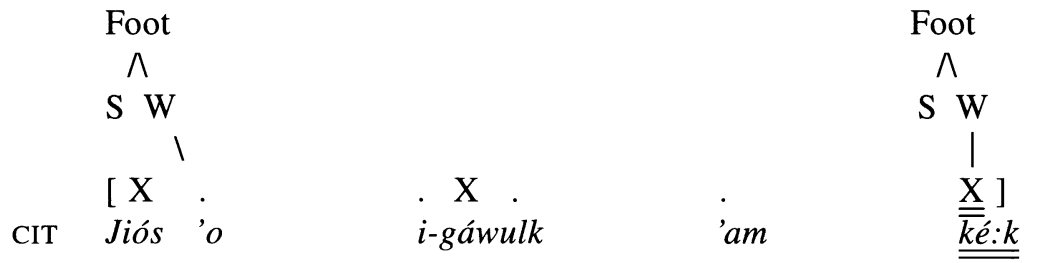

$\begin{array}{ccc}(20 b) & \begin{array}{c}\text { Foot } \\ /\end{array} & \\ & \mathrm{S} \quad \mathrm{W} & \\ & & \\ \text { SONG } & {[\mathrm{X}} & . \\ & \text { Nó-lig- } & \text { kam-e } \\ & \text { Nó-ligk } & \text { 'am } \\ \text { to turn } & \text { LOC }\end{array}$

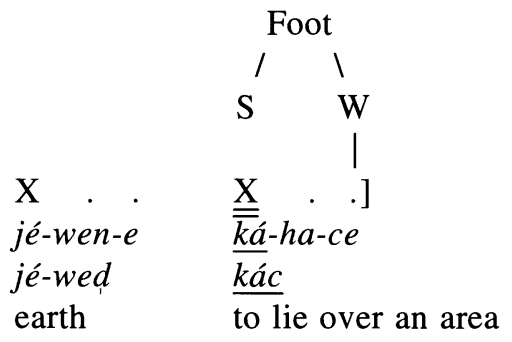

'Noligk lies there on earth'.
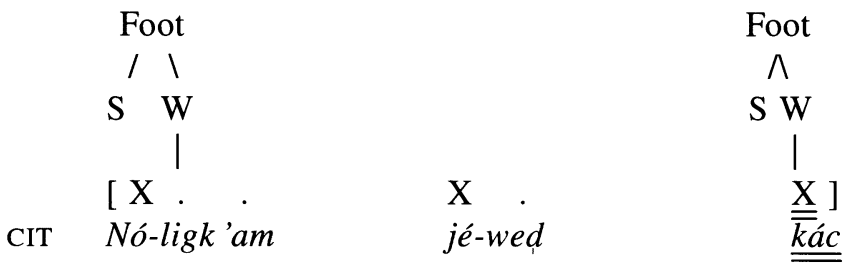

In (20) we see that the crucial violations of the Edge Constraint come in those lines where a stressed monosyllabic word falls line-finally (CITATION). The actual song lines (sONG) are without violation because the final word reduplicates. Vacuous Reduplication clearly prevents a violation of the Edge Constraint.

Let me now summarize this section. I have isolated the generalizations about edge effects and proposed the Edge Constraint to resolve these effects. The Edge Constraint has two parts: (1) it builds trochaic feet at each edge of a song line and (2) it prohibits stresses in the weak positions of feet. ${ }^{26}$ By building feet only at the edges, I have made a proposal which unifies the edge effects under one treatment. This analysis also has the benefit of allowing a characterization of the restriction on the final metrical

${ }^{26}$ This proposal means that the meter is characterizable in terms of binary FEET. Since the meter allows any number of unstressed syllables between the stressed syllables, I am not characterizing the meter itself as "duple" (or "triple" for that matter), but I am characterizing the feet invoked by the meter as binary. (Thanks to Donald Bahr for raising a related point in his review of this article.) 
position, which can be either odd or even, but is never filled with a stressed syllable. Finally, this analysis is compatible with the flexible length of the song line.

3.2. An account of adjacent stresses. Let me review the relevant facts about Vacuous Reduplication first. Recall from the first section that a stressed monosyllable will reduplicate when to the left of a stressed syllable or occurring line-finally. Because the Edge Constraint treats only those stresses appearing line-finally, the behavior of adjacent stresses must be accounted for. Crucially, Vacuous Reduplication creates an unstressed syllable between two stressed ones.

I propose that Vacuous Reduplication enables the meter to construct a binary trochaic foot which does not violate the Edge Constraint. Again, the proposal is simple: by adding a principle which builds binary feet from stresses, the Edge Constraint will rule out any illicit feet. However, for the Edge Constraint to apply, there must be feet. Recall that from the earlier discussion, I showed the difficulty of characterizing the final metrical position with the meter aligned to alternating $\mathrm{S}$ and $\mathrm{W}$ positions. In (21), I show song lines with Vacuous Reduplication aligned to a trochaic meter of alternating $\mathrm{S}$ and $\mathrm{W}$ positions. What we see is that the flexible line length complicates any attempt to characterize lines in terms of alternating strong and weak positions, because it is not always the case that the stressed syllable in a song line falls in an odd (S) position. The song line in (21c) places two stressed syllables in weak metrical slots.

(21) Examples of Vacuous Reduplication (underlined) by metrical position

(21a) $\mathrm{X}$

SONG $\frac{W a ́-w a i}{\mathrm{~S} \mathrm{~W}}$

\begin{tabular}{|c|c|}
\hline $\begin{array}{l}\mathrm{X} \\
g \hat{\imath}-w u \text {-lik- }\end{array}$ & $\begin{array}{l}\mathrm{X} \\
\text { nó-no-hà }\end{array}$ \\
\hline S W S W & S $\mathrm{C}$ \\
\hline
\end{tabular}

CIT $\begin{aligned} & \mathrm{X} \\ & \frac{\text { Wáw }}{\mathrm{S}}\end{aligned}$

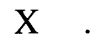

Gíwulk

W S

constricted
$\mathrm{X}$.

dó'ag

W S

mountain

'Constricted Rock Mountain'

$(21 b)$

SONG $\mathrm{Oi}$

$\mathrm{S}$
$\mathrm{X}$
$\frac{s o ́-s o}{\mathrm{SW}}$
$\mathrm{X}$

$\frac{k u ́:-k u:-\eta e}{\text { SW S }}$ 


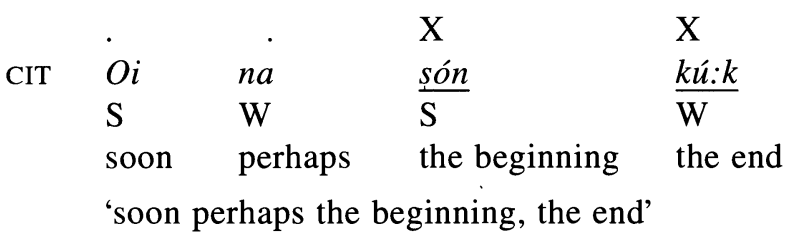

(21c)

SONG am

$\mathrm{S}$

\section{ha-wui}

W S

$\mathrm{X}$. .

hí-me-da

W S W

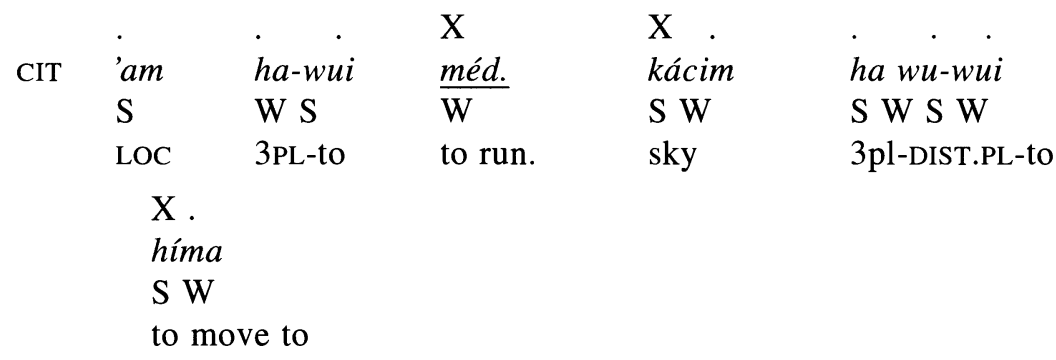

'They are running towards it. Towards them moves the sky'.

For $(21 a)$ and $(21 b)$, with two adjacent stresses in a citation line, the first of these occurs in a strong position and the second in a weak position. Presumably, the Edge Constraint will rule them out and Vacuous Reduplication will create the legal unstressed syllable for the weak position. ${ }^{27}$ Note that the song lines in (21) also place stressed syllables in strong positions. However, $(21 c)$ is problematic for such an account. In this example, both in the citation and the song line, it is the first stress of two adjacent stresses which falls in the weak position. If the stressed syllable of the metrical foot is indicated by S positions, we do not anticipate this result. Thus the stress patterns of song lines are poorly aligned to the metrical positions labeled above. This shows that the characterization of the meter as a string of alternating $\mathrm{S}$ and $\mathrm{W}$ positions is not completely accurate. A better characterization would consistently place the second of two adjacent stresses in weak

\footnotetext{
${ }^{27}$ The nature of Vacuous Reduplication deserves a comment. As it is prefixal, it actually allows the stress to move from one syllable to the newly created one. This has the ultimate effect, however, of creating a weak position in the meter. Also, the phonological changes found in songs, especially those related to features, nasalization, and lenition, are often reflected in the reduplicated forms. These changes are evident if one compares the citation and song forms.
} 
position. Merely alternating $\mathrm{S}$ and $\mathrm{W}$ positions misaligns stresses in song lines, as seen in (21c).

Here, I propose that the proper treatment of the metrical pattern is one which allows all stresses to appear in S position. This gives an adequate formal characterization of the prohibition on adjacent stresses; these stresses head binary feet. Binary feet consist of two positions. Any foot that fills both positions with stressed syllables lacks a $\mathrm{W}$ position, and thus violates the second component of the Edge Constraint above, which bans unfilled weak positions in the foot.

To achieve this effect, the meter requires one more constraint, which will effectively build binary feet wherever stresses appear. In (22), I formalize this rule:

(22) Binary Foot Constraint (applies to songs)

(22a) All stresses appear in the strong position of a foot.

(22b) All feet are binary (following Hayes 1987).

With the proposed Binary Foot Constraint (BFC) of (22), we also require a formalization of Vacuous Reduplication to reduplicate and prefix syllables that result in the eventual filling of the necessary weak positions by the BFC. I give this formalization in (23) (following McCarthy and Prince 1990). The formalism creates a prefixal reduplicant wherever a vacant position appears in a foot in the meter.

(23) Vacuous Reduplication (in this rule, són typifies the forms which participate in this process, that is, stressed monosyllables)

$\begin{array}{cc}\Sigma-: \Phi(\text { són })= & \Sigma-(\text { són } \\ & =\Sigma-(\text { són } \Phi) \\ & =\text { sósson } \\ \text { where: } \quad & \text { Foot } \\ & \wedge \\ & S \mathrm{~W} \\ & |\mathrm{X}|\end{array}$

The first line of the formalism specifies that this operation (namely, prefixal reduplication) applies when the target, són, appears in a given environment. The specific environment here is before a stressed word. When this environment applies, the second line of the formalism shows that there is reduplication. The third line shows the actual form that will surface as output of this rule, here śóson. Thus the rule in (23) will reduplicate monosyllables wherever they are not followed by an unstressed syllable. Note that stressed syllables cannot fill these positions, as this violates the second half of the 
Edge Constraint (18b). In the data in (24), I show the effects of the proposed BFC and Vacuous Reduplication. Note the empty weak positions (underlined) that result from the ban on a stress in weak position:

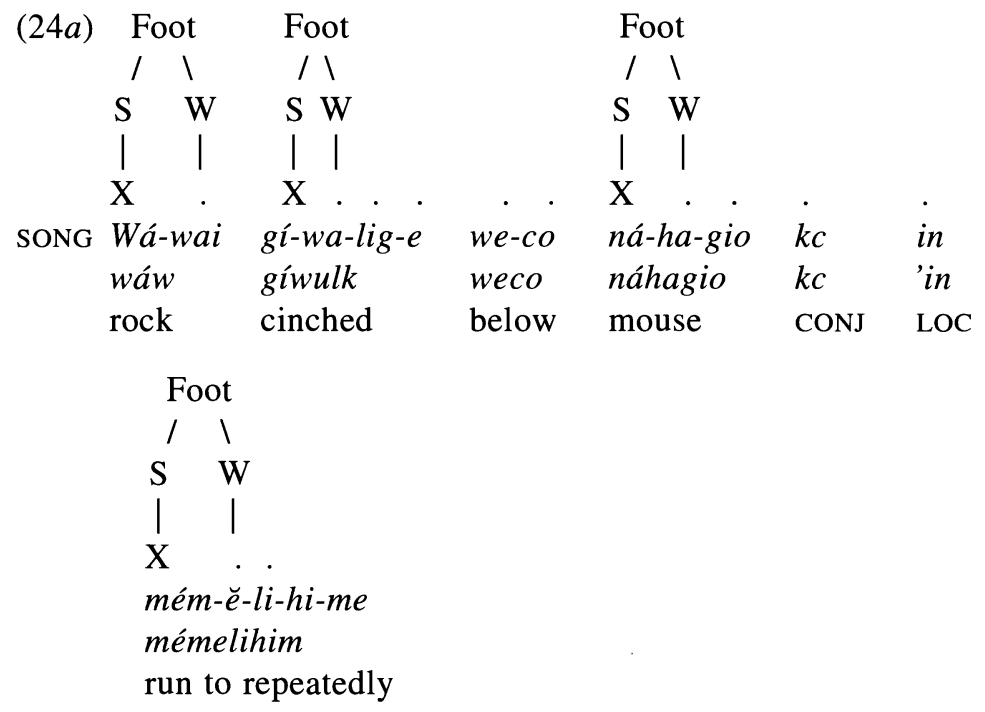

'The mouse runs around there below Cinched Rock'.

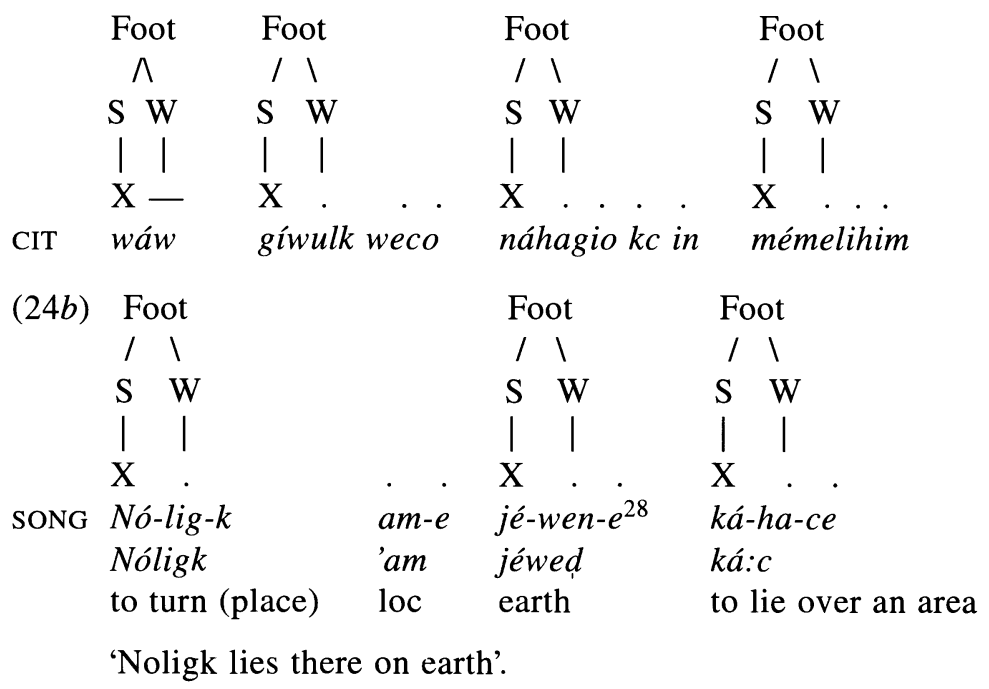

${ }^{28}$ This example also shows the ambiguity in how the meter treats jéwed. The form must be scanned as a disyllable here because it does not reduplicate. 


\begin{tabular}{|c|c|c|c|c|}
\hline & Font & & Eor & \\
\hline & 11 & & 11 & $\Lambda$ \\
\hline & $\mathrm{S} \mathrm{W}$ & & $\mathrm{SW}$ & $\mathrm{S} \mathrm{W}$ \\
\hline & 11 & & 11 & 11 \\
\hline & $\mathrm{X}$. & 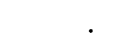 & X . & $X-$ \\
\hline CIT & Nóligk & 'am & jéwed & ká:c \\
\hline$(24 c)$ & & & Foot & Foot \\
\hline & & & $\wedge$ & 11 \\
\hline & & & S W & S W \\
\hline & & & 11 & 11 \\
\hline & . & . & $X$. & $X$ \\
\hline SONG & $o i$ & $n a$ & $S S o ́-s o$ & $k u ́-k u:-\eta e$ \\
\hline & $o i$ & & són & kú:g \\
\hline & soon & perhaps & the beginning & the end \\
\hline & soon pe & haps the 1 & ginning, the en & \\
\hline & & & Foot & Foot \\
\hline & & & $\Lambda$ & $\wedge$ \\
\hline & & & S W & \\
\hline & & & $\left.\right|_{x}$ & ${ }_{X}$ \\
\hline IT & $o i$ & na & són & $k u ́: k$ \\
\hline
\end{tabular}

The lines in (24) show several consequences of the second part (BFC; Vacuous Reduplication) of my proposal: (1) The second of two adjacent stresses cannot fill the weak position of the foot, following the Edge Constraint. (2) Line-final stresses cannot build binary feet to satisfy the BFC, for they have no material to fill the weak position. (3) All stresses will necessarily appear in strong positions. (4) The BFC and Vacuous Reduplication make redundant part of the Edge Constraint, specifically, building feet on right edges.

It is this final consequence which suggests that the Edge Constraint should be revised to build feet only at left edges. I give the simplified Revised Edge Constraint in (25).

(25) Revised Edge Constraint. Tohono O'odham song meter is governed by the following:

(25a) The left edges of song lines begin with a trochaic foot.

(25b) *Foot

$\wedge$

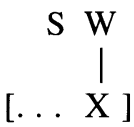


To conclude this section, the significance of the lines in (24) are that they confirm the intuition that Vacuous Reduplication is a metrical effect; the significance of the Binary Foot Constraint is that it explains why the extra syllable of Vacuous Reduplication is generated: to build satisfactory trochees. An additional benefit is that the BFC unifies the right-edge effects, the prohibition on adjacent stresses, and the effects of Vacuous Reduplication under the auspices of constraints that govern the meter. Thus, the BFC augments the Edge Constraint, and a highly complex, rigid system of meter emerges in the O'odham songs.

3.3. Consequences of the Constraints. Here, I briefly demonstrate why each part of the two constraints is necessary to rule out nonoccurring lines. There are three types of lines which never occur in the corpus; I give these below, followed by sample lines that are acceptable.

(26) Unacceptable lines

$(26 a) *$. X . . . . .

$(26 b) * \ldots \ldots \mathrm{X}$

$(26 c) * \ldots X$ X . . . .

Acceptable lines

$(26 d) \mathrm{X} \ldots \ldots \ldots$

$(26 e) \ldots \ldots \mathrm{X} \ldots \ldots$

(26f) X . X . . . . .

$(26 g) \ldots . . X . X$.

Which lines are judged acceptable and unacceptable by only application of the Revised Edge Constraint? Those in $(26 b)-(26 g)$ are all acceptable, while only $(26 a)$ is unacceptable. The line in (26a) is exactly the type of line the Revised Edge Constraint is meant to rule out. How do the lines fare in a comparable treatment with the Binary Foot Constraint? By the Binary Foot Constraint, the acceptable lines are $(26 a)$ and $(26 d)-(26 g)$ and the unacceptable ones are (26b) and (26c), shown in more detail in (27):
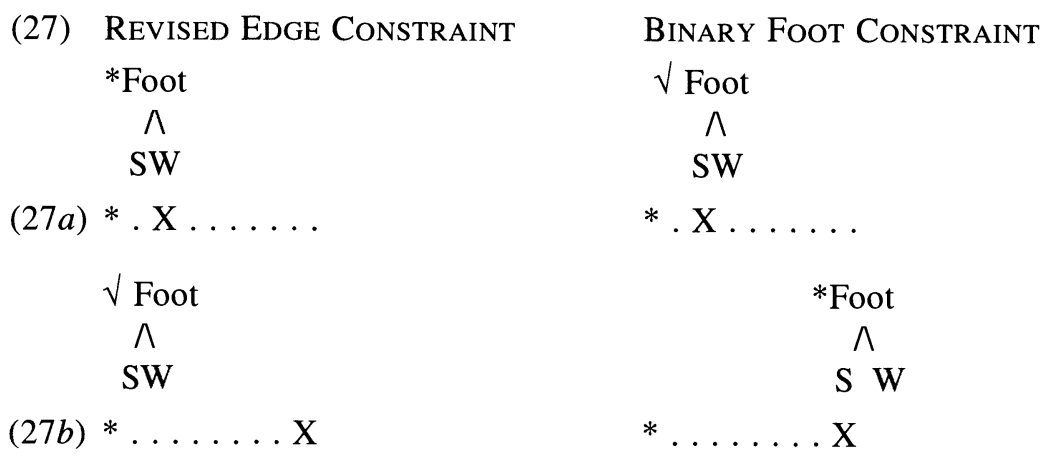


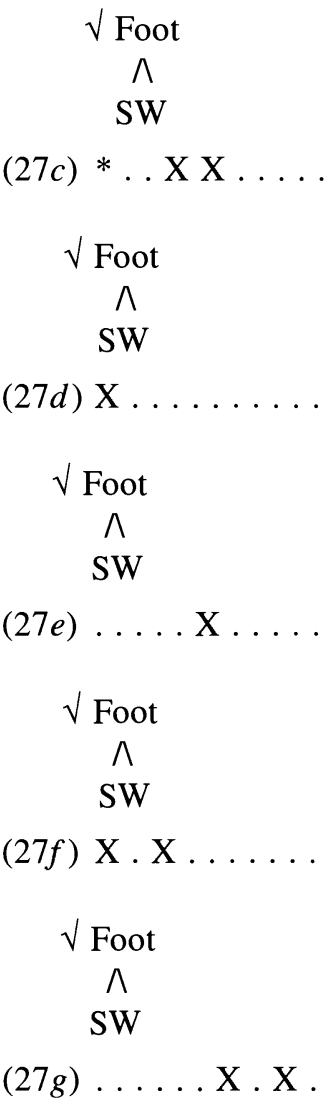

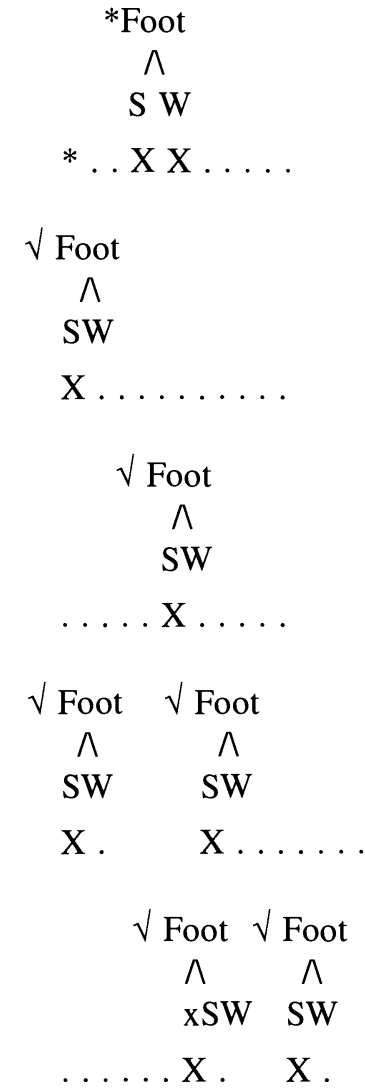

As (27) shows, the Revised Edge Constraint and the Binary Foot Constraint are both independently needed to account for different types of ungrammatical lines. Each rules out a different subset of the unacceptable lines. Note that for the acceptable lines, there is only overlap in lines like $(27 d)$ and $(27 f)$, which begin with a stressed syllable followed by an unstressed one. Here, both of the constraints build acceptable feet. This marginal overlap, however, is a consequence which is insignificant in view of the work both constraints do separately on unacceptable lines.

Let me quickly review the analysis presented in this section. My analysis consists of three parts: the Revised Edge Constraint, the Binary Foot Constraint, and Vacuous Reduplication. The Revised Edge Constraint consists of two parts: (1) all metrical song lines minimally begin with a trochaic foot and (2) stresses are prohibited in the weak positions of feet. This filter constrains the meter by restricting the left-edge position which does not allow stress, the second metrical position. The Revised Edge Constraint al- 
lows us to refer to this metrical position by using the Foot because there is no other category which covers the set of distributional facts. I argue that the Edge Constraint in its earliest version is further confirmed by the behavior of monosyllabic stressed words line-finally. For the Revised Edge Constraint, the manipulation of the stressed syllables by the morphology shows that the avoidance of the two positions is significant, and not that they were merely overlooked.

I further argue that the critical effect of Vacuous Reduplication is to create an extra syllable which results in separating two stresses by an unstressed syllable. This effect can also be characterized under the Revised Edge Constraint, if we make one crucial modification to the analysis. I have proposed that the Binary Foot Constraint effectively makes a binary foot for each stressed syllable. Here again we see how the Revised Edge Constraint rules out any foot with a stress in the weak position. Binary feet ensure that stressed monosyllables will never appear line-finally because they create degenerate feet. ${ }^{29}$ Thus the Binary Foot Constraint allows both a characterization of the distributional facts (no adjacent stresses, stress may fall in either even or odd metrical positions), as well as an account of Vacuous Reduplication which coheres with the entire metrical system of the songs.

This analysis of Tohono O'odham song meter enriches our understanding of metrical theory. There is no other way in which we can characterize the data presented here; the metrical categories of foot and line are strongly motivated and, indeed, we are able to construct a metrical theory using rather simple theoretical entities. Further, the system argues for strict binarity in the representation of the foot in meter.

4. On meter and universals. In this section I discuss Hayes's theory of meter with respect to the analysis presented in the previous section. Hayes (1989) claims that metrical requirements are lax line-initially. The analysis of TO requires modification of the typological claims made in Hayes (1989) because O'odham metrics requires strict left-edge metrical constraints.

\footnotetext{
${ }^{29}$ The meter does show surface dactylic (S W W) effects. This is seen at the right edge with respect to the extra vowels, as pointed out to me by Leanne Hinton and Gilbert Youmans. Forms such as ké:k surface as a dactyl when line-final: kéheka. Note that a dactylic account fails when we consider the fact that trisyllabic words, such as bijemid 'to surround, end with an extra vowel in the songs: $b i$-je-mi-da. Also, vowel-final disyllables may receive no additional syllables, as when $k a k-k e$ 'to ask' surfaces line-finally without change. The formalization of Vacuous Reduplication could easily be changed to produce dactyls for these types of words, as well as for adjacent and line-final stresses. The effects of Vacuous Reduplication clearly support a binary analysis. Finally, the form káidaghim 'resounding noise-CONT' truncates into a disyllable when it ends a line: káim-he. These facts are incompatible with a dactylic analysis of the meter.
} 
Let me review Hayes's rule typology. Three rule types make up "an exhaustive typology of the ways in which metrical rules may refer to bracketing. A given rule may belong to more than one type" (Hayes 1989:246). In (28), I list and define these three types:

(28a) Bounding RulE: "considers only those peaks ${ }^{30}$ that are defined within a given peak in a snapshot of that category" (Hayes 1989:245).

(28b) Right-Edge Rules: "apply to rule out structures of the following form:

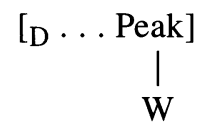

where ' $D$ ' is a specified prosodic domain, 'Peak' is a peak in metrical $W$ position defined within $D$, and '...' is material included in D that the rule may optionally specify. The claim here is that the right edges of prosodic categories are often scanned with special strictness" (Hayes 1989:245).

(28c) LEFT-EdGE Rules: "apply to configurations of the form

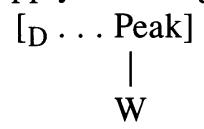

where 'Peak' and 'D' and '. . .' are defined as before. The difference here is that left edge rules, rather than forbidding a specified cadence, may overrule other metrical rules, licensing cadences that would otherwise be ill-formed" (Hayes 1989:245).

An interesting situation arises when we consider the Revised Edge Constraint. If we allow a loose definition of domain here, such that Foot and Line are allowed, the Revised Edge Constraint (25a) contradicts Hayes's claim for left edges as lax, because it provides that a foot must be built on the left edge of a line (to prevent a stress in weak position). This is never violated in the songs, robust evidence that left-edge rules for TO song meter are strict. The more general part of the Revised Edge Constraint (25b), which prohibits stresses in metrical W, is consistent with Hayes's formulation of right-edge rules. But crucially, it is the instantiation of this for the initial, left edges of song lines which contradicts his typological claim that left-edge rules are lax. The necessity of building a strict trochaic foot lineinitially supports the argument for a revision to the typology of rules to allow strict left-edge rules.

\footnotetext{
${ }^{30}$ Peak is defined as any syllable with a higher grid column than AT LEAST ONE of its neighbors (Hayes 1989:227).
} 
Finally, I would like to discuss the theoretical role played by the categories motivated in this paper: Foot and Line. Hayes notes that the "bracketed units Line, Colon, and possibly Foot are thus supported by the metrical rules that must refer to them" (1989:256). A central point of this paper is the motivation of the Foot as a category referred to by metrical rules. Kiparsky (1977), ${ }^{31}$ Prince (1989), and Youmans (1989) (and others) also provide evidence for the Foot. The second comment is that while Hayes acknowledges that the Metrical Hierarchy (made up of Line, Colon, Foot) plays a role in meter, he observes that the metrical rules referring to categories of the Metrical Hierarchy follow the typology of metrical rules which he proposes. Again, however, I argue that the study here shows that line-initial strictness must be allowed.

5. Conclusion. In this paper, I have argued a number of points. Let me review them, starting with those of a more descriptive nature. The data involved in this study are very complex, and I have attempted to organize the various phenomena in the songs according to their relevance to the meter, because that is the focus of this paper. Tohono O'odham songs are made up of lines which are flexible in some ways and rigid in others. The line is flexible in allowing a relatively unconstrained number of stresses and syllables.

Vacuous Reduplication shows itself to be metrically motivated. I have shown that it involves the systematic manipulation of the morphology to avoid adjacent or line-final stresses.

The descriptive facts of Tohono O'odham songs reveal the dual nature of the line: it is flexible in terms of the number of stresses and syllables; it is rigid in terms of regulating where stresses may appear. The closest parallel can be found in Old English poetry, such as Beowulf. The meter of Beowulf has typically been described as a line which consists of two VERSES, which in turn are made up of two main stresses and an unspecified number of more weakly stressed syllables. ${ }^{32}$ However, unlike TO song meter, the meter of Beowulf can be characterized by the regularity of the number of stresses.

In O'odham song meter, the regularity is derived differently; it is derived through restrictions on where main stresses may appear. Unlike other meters which regulate this characteristic, Tohono O'odham song meter does not regulate line length. Like Beowulf, this results in a meter which allows an indeterminate number of syllables of lesser prominence. The characterization of the O'odham song meter may exemplify a novel system of meter.

\footnotetext{
${ }^{31}$ However, see Hayes (1983) for arguments against Kiparsky's analysis.

${ }^{32}$ However, both Cable (1974) and Russom (1987) argue against this "textbook" characterization of the meter and propose their own alternatives.
} 
This finding alone is an important one for the typology of versification systems.

The metrical system can be captured in an analysis which relies on the foot. The foot-based analysis also provides for the line's flexibility. The O'odham meter shows that these components are necessary for generative metrics.

I have made two specific proposals the cornerstone of my analysis. First, I argued for the Revised Edge Constraint, which proposes that the prohibition on stressed material in the second metrical position can be handled only by building a foot at the beginning of each song line and restricting stresses from appearing in the weak position. Second, I showed that the additional restrictions on the line, namely, the prohibitions on stresses appearing adjacent to each other or line-finally, can be derived by the Binary Foot Constraint, which states that all feet are binary trochees and all stresses must appear in strong position of feet.

Under my analysis, the flexibility in song lines comes from the fact that the meter only regulates stressed syllables; weak syllables are relevant only when they are incorporated into feet by the Revised Edge Constraint or the Binary Foot Constraint. All other weak syllables in the line are unrestricted. This results in the variability of line lengths seen in the songs.

Three central theoretical points have been developed here. First, I show that the line may be flexible in some poetic traditions. Second, I argue that binary feet, with constituency, are needed in this line. Finally, I argue that Tohono O'odham songs attest to the existence of strict metrical rules for left edges. The necessity of beginning each line with a foot, to ensure the strict enforcement of no stresses in the second metrical position, provides the impetus to revise the typology of meter presented in Hayes (1989), who argues for a typology of metrical rules that states that left-edge rules are lax. The importance of this study from a typological perspective is evident.

In conclusion, this study has isolated certain problem areas in generative metrics, as well as providing evidence for a novel system of versification. By using data from Tohono O'odham, a Native American language steeped in the oral tradition, we can see not only where metrical theory is lacking but also recognize the unique properties of the system of meter used in these songs. The metrical system is rooted in three simple principles (the Revised Edge Constraint, the Binary Foot Constraint, and Vacuous Reduplication) which produce the intricately organized metrical pattern, the meter of Tohono O'odham songs.

\section{REFERENCES}

Attridge, Derek. 1982. The Rhythms of English Poetry. Essex: Longman House.

BAHR, DonALD. 1980. Four Papago rattlesnake songs. Arizona State University Anthropological Research Papers 20:118-26. 
1983. A format and method for translating songs. Journal of American Folklore 96:170-82.

Cable, Thomas. 1974. The Meter and Melody of Beowulf. Urbana: University of Illinois Press. 1991. The English Alliterative Tradition. Philadelphia: University of Pennsylvania Press.

CHEN, MichaEl. 1979. Metrical structure: evidence from Chinese poetry. Linguistic Inquiry $10: 372-420$.

Chesky, Jane. 1943. The nature and function of Papago music. M.A. thesis, University of Arizona.

CRystal, David. 1991. A Dictionary of Linguistics and Phonetics. Cambridge, Mass.: Basil Blackwell.

Fitzgerald, Colleen M. 1993. Too many vowels: the phonology of syllables in Tohono O'odham songs. Paper delivered at the Twenty-third Western Conference in Linguistics, Seattle, Washington.

1994. Prosody drives the syntax. Proceedings of the Twentieth Annual Meeting of the Berkeley Linguistic Society, pp. 173-84. Berkeley: Department of Linguistics, University of California.

1997a. O'odham rhythms. Ph.D. dissertation, University of Arizona.

$1997 b$. Evidence for headless feet in metrical theory. Paper presented at the annual meeting of the Linguistic Society of America, Chicago.

Haefer, J. Richard. 1977. Papago Music and Dance. Music and Dance Series, Occasional Papers, vol. 3, no. 4. Albuquerque, N.M.: Navajo Community College Press. Urbana.

1981. Musical thought in Papago culture. Ph.D. dissertation, University of Illinois,

Hale, Kenneth. 1959. A Papago grammar. Ph.D. dissertation, Indiana University.

Halle, Morris, and Samuel J. Keyser. 1971. English Stress: Its Form, Its Growth, and Its Role in Verse. New York: Harper \& Row.

Halle, Morris, and Jean-Roger Vergnaud. 1987. An Essay on Stress. Cambridge, Mass.: The M.I.T. Press.

HAMmOND, MichaEl. 1988. Constraining Metrical Theory: A Modular Theory of Rhythm and Destressing. New York: Garland.

1991. Poetic meter and the arboreal grid. Language 67:240-59.

HAYES, BRUCE. 1983. A grid-based theory of English meter. Linguistic Inquiry 14:357-93. 1987. A revised parametric theory. Proceedings of the Northeastern Linguistic Society 17:274-89.

1989. The prosodic hierarchy in meter. Phonetics and Phonology: Rhythm and Meter, ed. P. Kiparsky and G. Youmans, pp. 210-60. New York: Academic Press.

1993. Metrics as an optimization problem: the case of English folk songs. Paper presented at Optimization Workshop, Rutgers University.

Hill, Jane, AND Ofelia ZePeda. 1992. Derived words in Tohono O'odham. IJAL 58:355404.

Hinton, Leanne. 1980. Vocables in Havasupai music. Southwestern Indian Ritual Drama, ed. C. F. Frisbie. Albuquerque: University of New Mexico Press. 1984. Havasupai Songs: A Linguistic Perspective. Tubingen: Gunter Narr.

1990. Song metrics. Proceedings of the Sixteenth Annual Meeting of the Berkeley Linguistic Society, Parasession on Native American Languages. Berkeley: Department of Linguistics, University of California.

Hymes, Dell. 1981. In Vain I Tried to Tell You. Philadelphia: University of Pennsylvania Press.

KIPARSKY, PAUl. 1968. Metrics and morphophonemics in the Kalevala. Studies Presented to Professor Roman Jakobson by His Students, ed. C. Gribble, pp. 137-48. Cambridge, Mass.: Slavica. 
1975. Stress, syntax and meter. Language 51:576-616.

. 1977. The rhythmic structure of English verse. Linguistic Inquiry 8:189-441.

MaLING, JoAN. 1973. The theory of Classical Arabic metrics. Ph.D. dissertation, Massachusetts Institute of Technology.

MATHIOT, MADELEINE. 1973. A Dictionary of Papago Usage. Bloomington: Indiana University.

MCCARTHY, John, AND AlAN PRINCE. 1990. Foot and word in prosodic morphology: the Arabic broken plural. Natural Language and Linguistic Theory 8:209-84.

1993. Prosodic morphology I. Ms., University of Massachusetts, Amherst and Rutgers University.

OehrLe, Richard. 1989. Temporal structures in verse design. Phonetics and Phonology: Rhythm and Meter, ed. P. Kiparsky and G. Youmans, pp. 87-119. New York: Academic Press.

Prince, Alan. 1989. Metrical forms. Phonetics and Phonology: Rhythm and Meter, ed. P. Kiparsky and G. Youmans, pp. 45-80. New York: Academic Press.

Prince, Alan, and Paul Smolensky. 1993. Optimality. Ms., Rutgers University and University of Colorado.

Russom, GeOFfREY. 1987. Old English Meter and Linguistic Theory. New York: Cambridge University Press.

SaXton, DeAn. 1963. Papago phonemes. IJAL 29:29-35.

SAXTon, D.; L. SAXTON; AND S. Enos. 1989. Dictionary: Papago/Pima-English, EnglishPapago/Pima. Tucson: University of Arizona Press.

UnderhILl, RUTH. 1938. Singing for Power: The Song Magic of the Papago Indians of Southern Arizona. Berkeley: University of California Press.

Wallace, Margaret, trans. 1981. O'odham Ha-Ñeñei (Papago Songs). Waitsburg, Wash.: San Simon School, Coppei House Publisher.

Youmans, Gilbert. 1989. Milton's meter. Phonetics and Phonology: Rhythm and Meter, ed. P. Kiparsky and G. Youmans, pp. 341-79. New York: Academic Press.

ZePEDA, OfELIA. 1988. A Papago Grammar. Tucson: University of Arizona Press. 